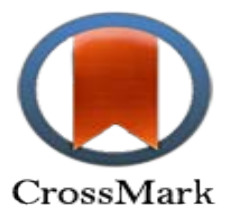

click for updates

\title{
The effect of listening to tavasol prayer on death anxiety in older adult
}

\author{
Afshar $\mathrm{M}^{1}$, Zandian $\mathrm{Sh}^{2},{ }^{*}$ Mirbagher Ajorpaz $\mathrm{N}^{3}$
}

1- Trauma Nursing Research Center, Department of Nursing and Midwifery, Kashan University of Medical Sciences, Kashan, Iran.

2- Trauma Nursing Research Center, Department of Nursing and Midwifery, Kashan University of Medical Sciences, Kashan, Iran.

3- Autoimmune Diseases Research Center, Department of Nursing and Midwifery, Kashan University of Medical Sciences, Kashan, Iran (Corresponding author)

Email: mirbagher_n@kaums.ac.ir

\section{Abstract}

Introduction: Anxiety of death is a real anxiety and one of the most components in the mental health of people, especially the elderly. Prayer therapy is a traditional intervention to alleviate disease and promote health. Therefore, the present study was conducted to determine the effect of listening to prayer on death anxiety of elderly in Kashan.

Method: This clinical trial study was performed on 70 elderly in Kashan, 2019. Patients were randomly assigned to control and intervention groups. Before intervention, demographic data and death anxiety questionnaires were completed by patients in both groups. In the intervention group, during one month, every other day (three times a week) after the Maghreb and Esha prayers at the Saraallah Mosque in Kashan, the Tavasol prayer was recited with the voice of Haji Mehdi Samavati through a speaker. The control group did not receive any intervention. The death anxiety questionnaire was completed again immediately after the end of the intervention and one month later in two groups. Data were analyzed using ANOVA, Chi-square and independent and paired t-test in SPSS v.16 software.

Results: The results showed that there was no significant difference in demographic data and mean score of death anxiety before intervention between the two groups $(\mathrm{P}>0.05)$. There was a significant difference in the mean score of death anxiety in the two groups $(\mathrm{P}<0.05)$ immediately after the sessions and one month after the intervention. The results of the repeated measures ANOVA showed that the mean changes of death anxiety varied over time and the interaction between group and time was significant for the variable of death anxiety $(\mathrm{P}<0.05)$.

Conclusion: The results of this study showed that listening to Tavasol prayer will improve the death anxiety of elderly. Therefore, prayer therapy may be a useful and effective intervention to improve the death anxiety of elderly.

Keywords: Prayer, Death Anxiety, Elderly.

Received: 16 November 2019

Accepted: 21 December 2019 


\title{
بررسى تأثير توش دادن به دعاى توسل بر اضطراب مر سى سالمندان كاشان
}

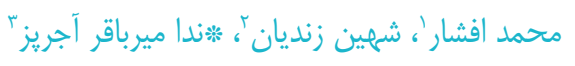

ا - مركز تحقيقات تروما، دانشكده برستارى و ومامايى، دانشكاه علوم يزشكى كاشان، كاشان، ايران.

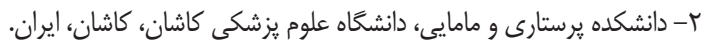

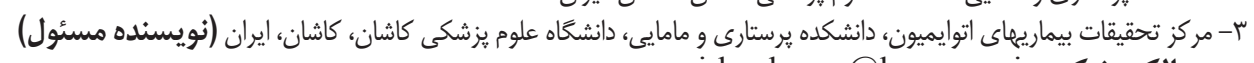
يست الكترونيكى: mirbagher_n@kaums.ac.ir

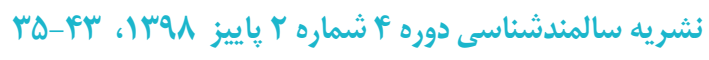

مقدمه: اضطراب مرك يكى اضطراب واقعى و يكى از مهمترين مولفه ها در سلامت روانى افراد بويزه سالمندان است. دعا درمانى يكى

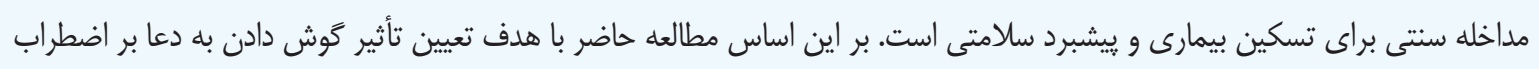
مرك سالمندان كاشان انجام شد.

روش: اين مطالعه از نوع كارآزمايى بالينى است كه بر روى • V سالمند شهر كاشان در سال شوسا انجام شد. بيماران با استفاده از

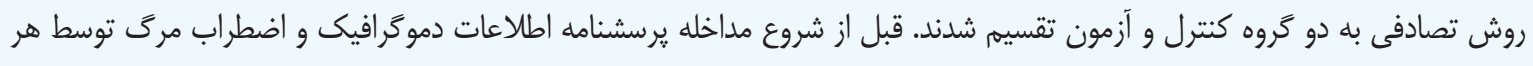

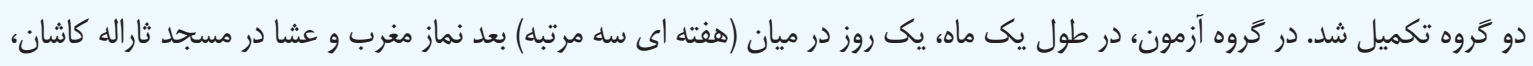

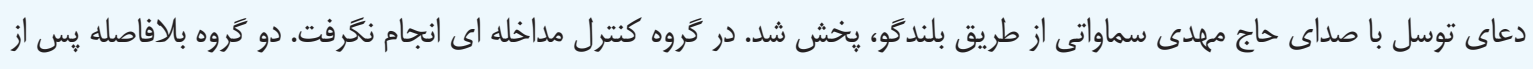

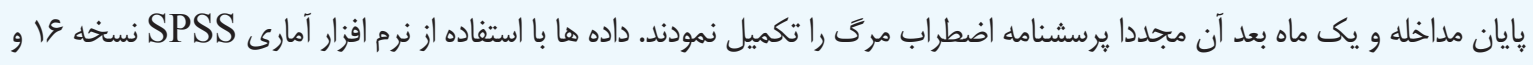

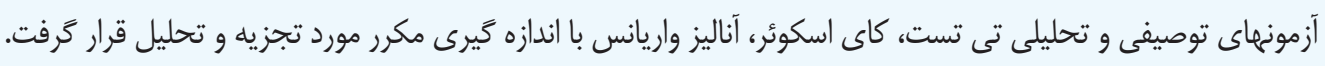

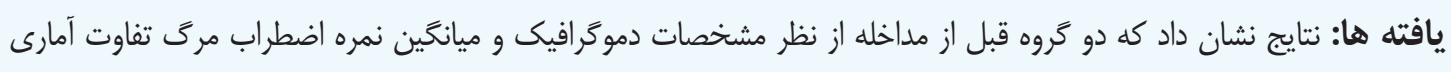

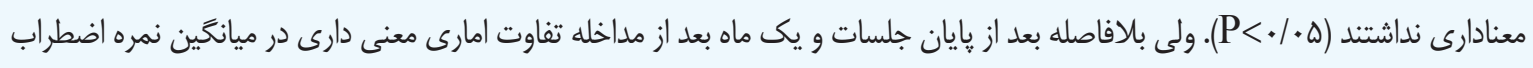

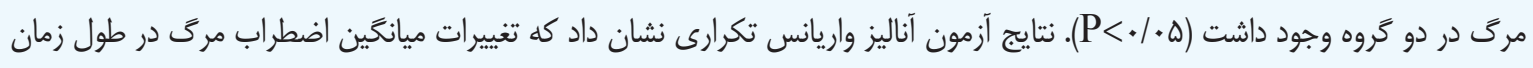

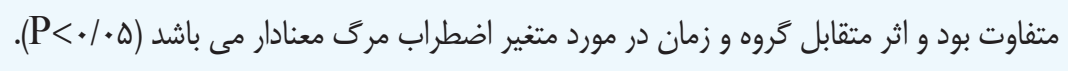

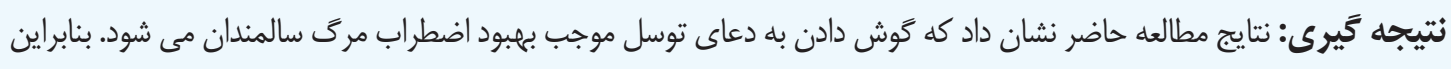

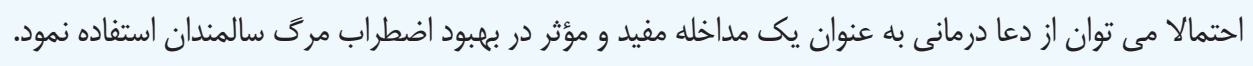
كليدوازه ها: دعا، اضطراب مركى، سالمند.

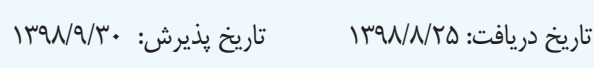

و اين ترس و اضطراب به نوعى در افراد سالمند به مراتب بيشتر از از

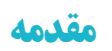

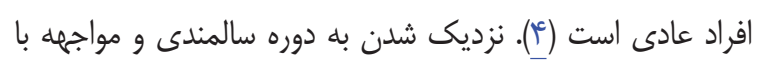

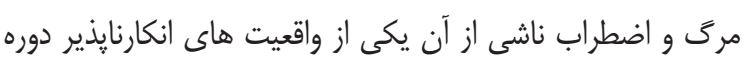

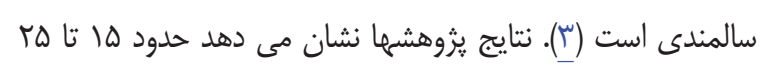
درصد افراد مسن دهار مشكلات روانى مهمى هستند و از اختلالاتى لتانى

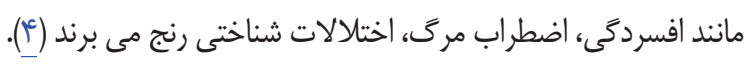

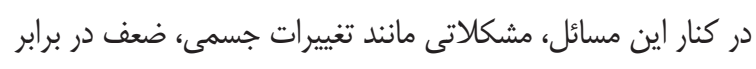

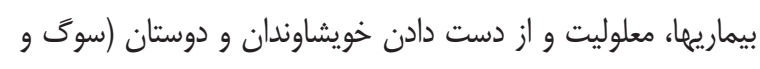

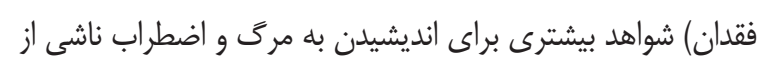

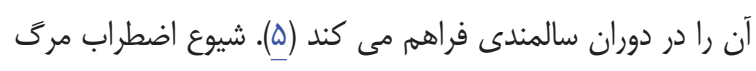

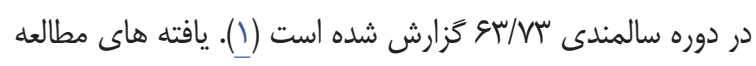

اضطراب مركى مشتمل بر افكار، ترس ها و هيجانات مرتبط

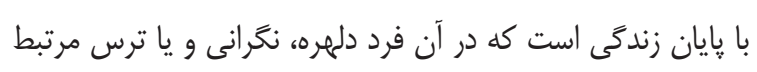

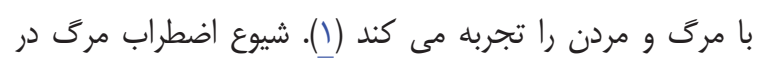

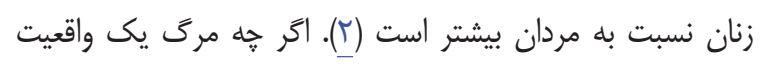

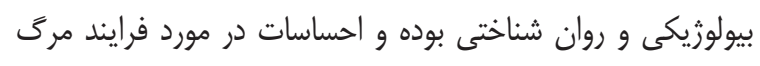

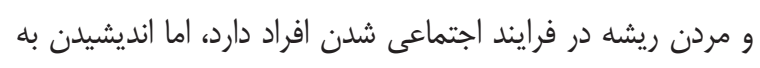

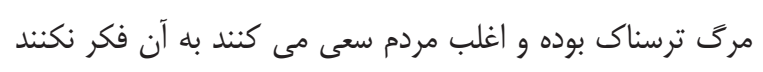

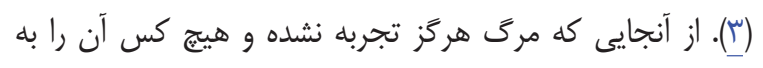

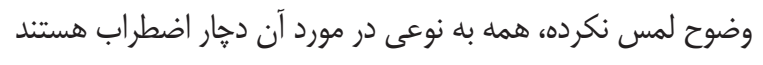


مى كند (II). طبق نظر كويئنَ از دانشخاه دوك، هنگام دعا ترشح هورمون هاى كورتيزول، إيى نفرين و نورايى نفرين متوقف شده و سيستم دفاعى بدن تقويت و در نتيجه باعث آرام شدن فرد مى كر دد نعرد

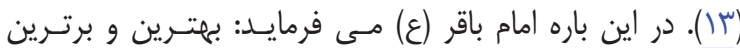

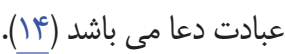
يكى از دعاهايى كه در دين اسلام سفارش زيادى به آن شده است، دعاى توسل است كه در קُندين مطالعه اثر بخشى آن در حيطه هاى سلامت روان دانشجويان (ها)، كيفيت زندگى بيماران سرطانى (ع)1)، اضطراب مادران داراى كودكان سرطانى (IV) بيان شده است. در مطالعات بالا دليل استفاده از دعاى توسل خاصيت آرامبخشى دعا، توسل به ז I امام و واسطه قرار دادن آنها بين خود و خدا، درك راحت

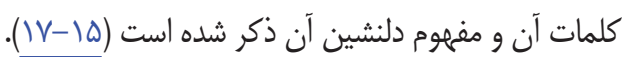
مطالعات نشان مى دهد كه بين ارتباط قوى با خداوند و اعمال مذهبى و نحوه واكنش افراد به رويدادهاى تنش زا و مشكلات

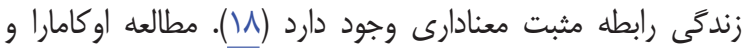

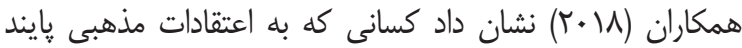
بودند، اضطراب و ناراحتى كمترى را نسبت به كسانى كه اعتقادات مذهبى زيادى نداشتند تحمل كردند (19). همجنين مطالعه فراهانى و همكاران در سال r إr نشان داد خواندن دعاى توسل باعث كاهش

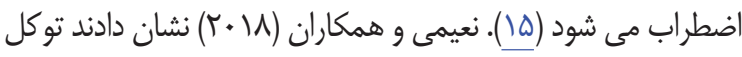

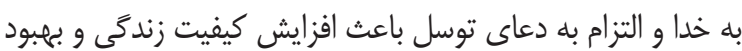
علائم روانشناختى در سالمندان داراى ييس ميكر مى شود (•r). مطالعه شريف نيا و همكاران نشان داد خواندن دعاى توسل باعث

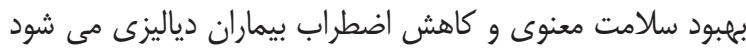

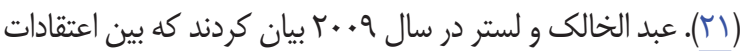
مذهبى و توسل به خدا با اضطراب مرك ارتباطى وجود ندارد و اعتقاد به مذهب و توسل به خدا نمى تواند اضطراب مركى را در بيماران

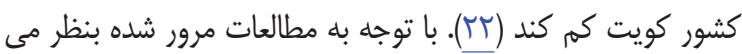
رسد موضوع ترس و اضطراب مرگ از جمله عواملى است كه در يثزوهش هاى مرتبط با ارتباط با خدا مورد غفلت قرار گرفته است و و يثوهشها در زمينه ارتباط با خدا (خواندن و گَوش كردن به دعا) و و اضطراب مركى در سالمندان كم مى باشد. بطور كلى با توجه به اينكه يكى از جالشهاى مهم دوران سالمندى ترس از مركى و اضطراب مردن مى باشد و اين متغير نقش مهمى در حفظ سلامت روانى و

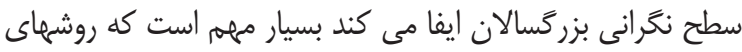
غير دارويى براى كنترل اين اضطراب استفاده كَردد. بنابراين با توجه به اثرات مفيد دعاى توسل از جمله آرامش بخش بودن دعاو مؤثر

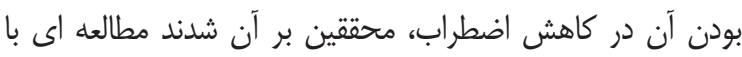

زراعتى و همكاران (هوس|) بر روى سالمندان مقيم و غير مقيم در سراى سالمندان شهر تهران نشان داد، ميانكَين اضطراب مرك در

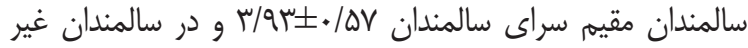

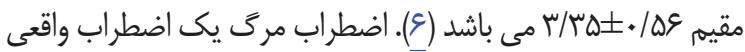
و يكى از مهمترين مولفه ها در سلامت روانى افراد بويزه سالمندان إنساب

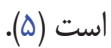

از آنجا كه اضطراب مركى از نظر روحى و روانى سالمند را

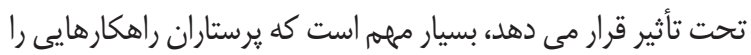
براى افزايش راحتى و كاهش تنش و اضطراب بيماران مد نظر قرار دهند. امروزه تمايل به استفاده از روشهاى غير دارويى جهت تسكين اضطراب مرگ رو به افزايش است (V). از بين درمانهاى غير دارويى مى توان تن آرامى، حساسيت زدايى، توقف فكر، سرمشق دهى، دعا

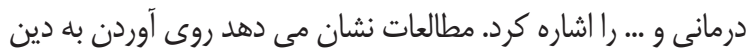
و مذهب و دعا، ترس از مرگ را كاهش مى دهد (V). شواهد حاكى از

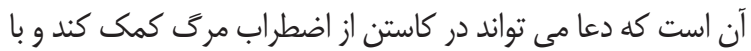

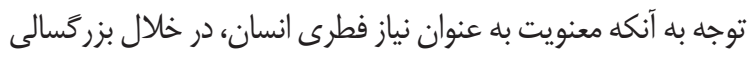
افزايش مى يابدو سالمندان در اين دوره به دعاو معنويت بيشتر توجه مى كنند، از اين رويكرد در درمان اضطراب مى توان بهره برد (^).

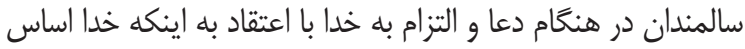
ايمنى است، احساس قدرت مى كنندو اعتماد به نفس شان در هنخام اضطراب و ترس افزايش مى يابد كه مى تواند باعث بهبود كيفيت

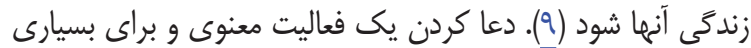
از افراد يك فعاليت مذهبى است. همجنان كه در همه لى مذاهب، توسل به خدا با دعاها و آيات مخصوص رايج است، در اسلام نيز اين

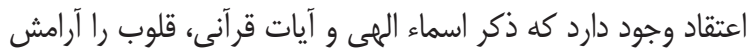
بخشيده و در معالجه امراض مؤثر است و ناكفته نماند كه شفايابى با مصلحت المىى و درجه اخلاص و ايمان انسان مربوط مى باشد (^). امروزه اعتقاد بر اين است كه دعا نوعى راهبرد است كه به به وسيله آن مردم مى توانند انواع مسائل زندگى خود را هدايت كنند، ويليامز جيمز بنيانكذار روانشناسى در آمريكا بيان مى كند: ايمان بدون شكى مدانس

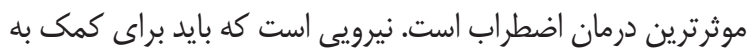

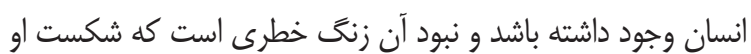
را در برابر سختيهاى زندكى هشدار مى دهد (•+). دعاو نيايش يكى مداخله سنتى براى تسكين بيمارى و ييشبرد سلامتى است كه به صورت فردى يا دسته جمعى انجام مى شود (1)(1). نتايج تحقيق دالاى و اكمن از مركز يزشكى دانشكاه كاليفرنيا در سانفرانسيسكو نشان داد دعا فعاليت بخشى از مغز موسوم به الهابه

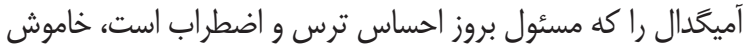


رجبى و بحرانى در سال •^ץ" آن را بر روى مسا دانشجو در شهر اهواز بررسى كرده و همسانى درونى آن را سل درصد تزارش نموده

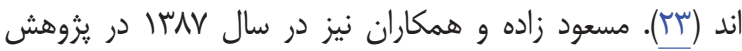
خود ضريب همبستخى سئوالات اين يرسشنامه را هو درصد كزارش

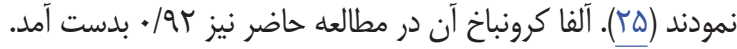
IR.KAUMS.) يس از كسب تاييديه كميته اخلاق

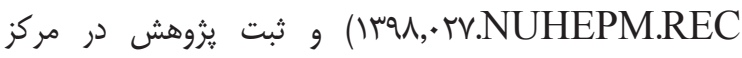
كارآزمايى بالينى به شماره IRCTr+1IIT و همجينين كَرفتن معرفى نامه از معاونت محترم يزوهشى، يُوهشكر

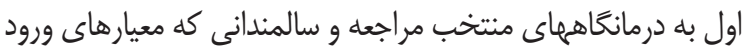
به مطالعه را داشتند، را انتخاب و وارد مطالعه كرد. سيس ازئس از آنها رضايت نامه آكاهانه مبنى بر شركت در يزوهش كَرفته شد و بها آنان آناسنا اطمينان داديم كه اطلاعات آنان محرمانه مى ماند. سبّ ستر سالمندان

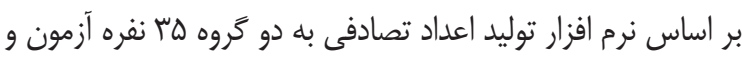
كنترل تقسيم شدند. در طى جلسه اول اهداف و نحوه اجراى يزوهش براى واحدهاى يزوهش توضيح داده شد. گروه آزمون يك روز در ميان (هفته اى سه مرتبه) در زمان نماز مغرب و عشا در مسجد ثاراله كاشان حضور ييدا مى كردند و دعاى توسل با صداى حاج مهدى سماواتى (به علت صداى شيوا و لحن آرامش بخش آن) همراه با دان

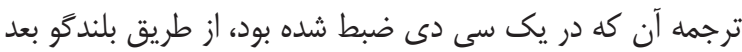

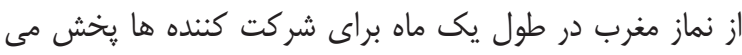

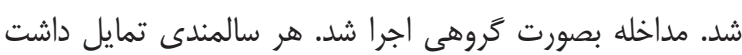
مى توانست در زمان קخشش دعاى توسل كتاب دعا هم در دست

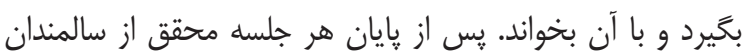

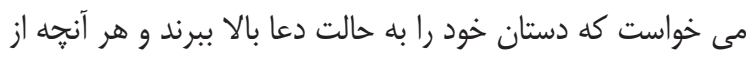
خدا مى خواهند در دل زمزمه كنند. در هر جلسه بله كروه آزمون دعوت نامه اى داده مى شد كه در آن تاريخ، ساعت و محل تشكيل جلسات دعاى توسل جهت يادآورى

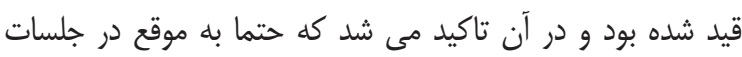

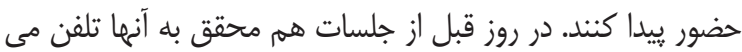
زد و تاكيد مى كرد كه در جلسات حضور يابند. كسانى كه مشكل

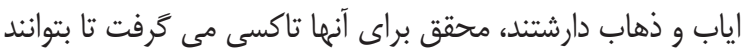

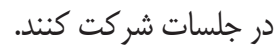
در گروه كنترل مداخله اى صورت نكَرفت و اقدامات روتين قبلى (خواندن نماز و دعا طبق روتين قبلى خود سالمند) انجام مى شد. دو گروه از نظر متغيرها همانند سازى شدند. براى ايجاد

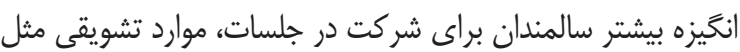

هدف تعيين تاثير گَوش دادن به دعا بر اضطراب مرك سالمندان

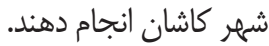

\section{ووش مطالكه}

مطالعه حاضر از نوع كارآزمايى بالينى بود. جامعه ى آمارى

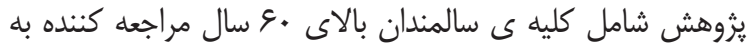
سه مركز بهداشتى متينى، اكرميان، كَلابجى شهر كاشان در سال

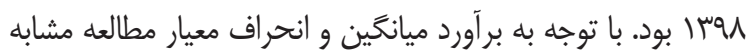

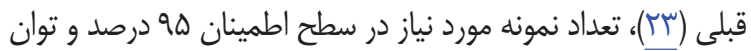

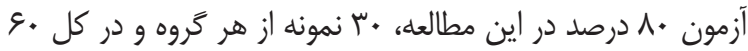

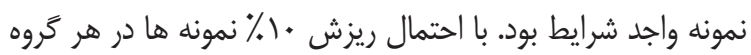

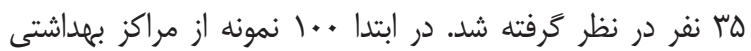

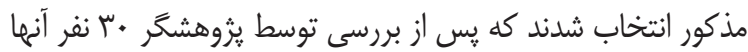

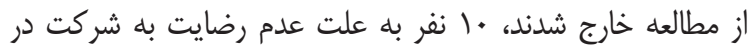

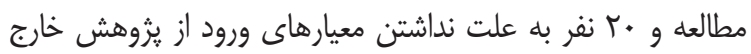
شدند. سيس •V • نمونه باقى مانده بطور تصادفى در دو كَروه آزمون

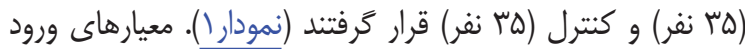
شامل سالمندان مسلمان كه سن •ع سال و بالاتر دارند، كسب نمره

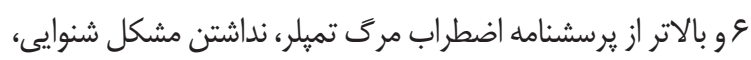
عدم مصرف داروهاى ضداضطراب، توانايى تكله، عدم سابقه مصرف

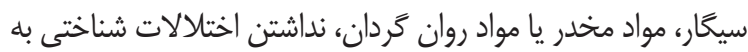
تشخيص يزشك متخصص، نداشتن اضطراب مرك خيلى شديد و مصرف دارو به علت آن، تمايل به شركت در يزوهش بون بود. معيارهاى خروج شامل غيبت در بيش از دو جلسه، عدم تمايل بيمار به ادامه شركت در مطالعه، كوش ندادن به دعا در هنخام يخش دعا، درا، استفاده همزمان از ساير روشهاى تسكين اضطراب مثل ورزش درمانى، اب دران

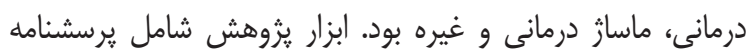
اطلاعات دمو مرافيك (سن، جنس، تأهل، تحصيلات، تعداد فرزندان، سابقه بيمارى زمينه ای) و يرسشنامه اضطراب مرك تميلربود. اين

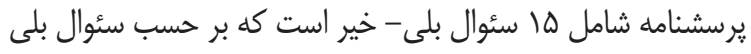
يا خير به آن نمره ا يا · تعلق مى گيرد (نمره ا در صورتيكه ياسخ فرد نشان دهنده وجود اضطراب مرك باشد و نمره صفر در صورتيكه

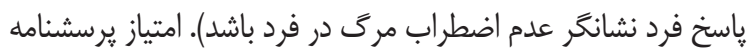
از صفر (عدم وجود اضطراب مرك) تا ها (اضطراب مركى خيلى بالا) كه حد وسط آن (Y-V) نقطه برش در نظر كرفته مى شود (YY) هاى مختلف جهت سنجش اضطراب مرك مورد استفاده قرار گرفته است و در كشور ايران ترجمه و روانسنجى شده است. بطور مثال 
و پاسخ هاى وى علامت زده مى شد. در پايان مطالعه نتايج مطالعه به اطلاع گروه كنترل و گروههاى ذينفع (ساير سالمندان، درمانخاهما و غيره) رسيد. نتايج بر اساس آزمونهاى كاى اسكوئر، تى تست، آنوا با اندازگيرى تكرارى تجزيه تحليل شد. سطح معنى دارى كمتر از

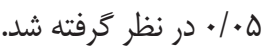

يذيرايى شير، جك قند خون، كنترل فشارخون، دادن هديه كوجى براى آنها در هر جلسه در نظر گرفته شدد. قبل، بلافاصله يس از يايان

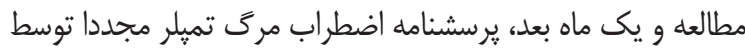
شركت كنندكان در يُوهش تكميل و نتايج در دو گروه با هم مقايسه

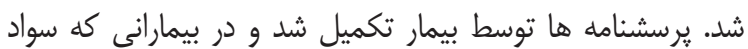
خواندن يا نوشتن نداشتند، سوالات توسط محقق براى بيمار خوانده

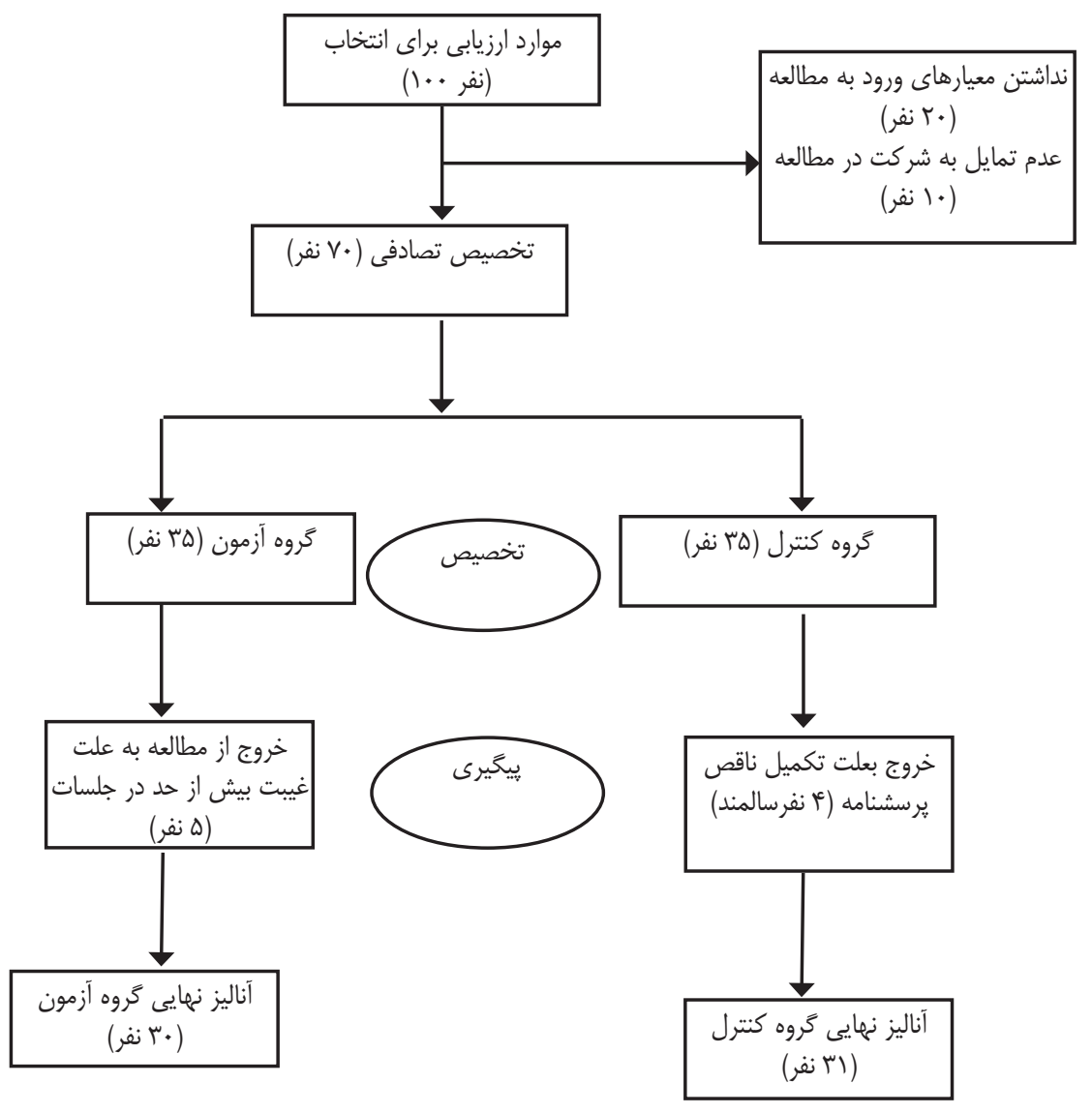

نمودار (: نحوه انتخاب و تخصيص و ييگيرى جامعه مورد مطالعه

نتايج آزمون تى تست نشان داد كه دو كَروه قبل از مداخله

كافتنه ها

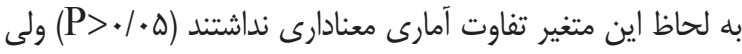

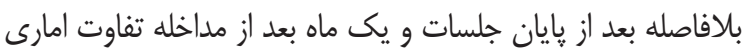
معنى دارى در ميانگين هاى نمره اضطراب مرك در دو گروه وجود

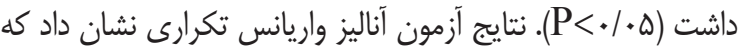
تغييرات ميانگَين اضطراب مرگ در طول زمان متفاوت بود. همجنين

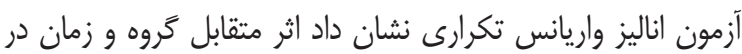

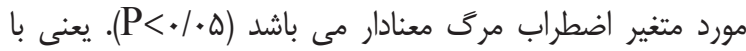

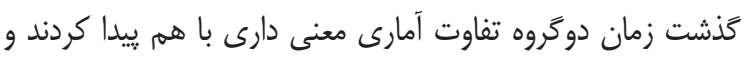

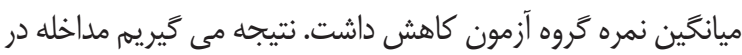

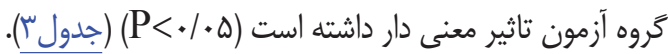

ريزش نمونه ها در طول مطالعه در گروه آزمون و كنترل به ترتيب أ و ه نفر بود. علت ريزش نمونه ها در گروه آزمون عدم

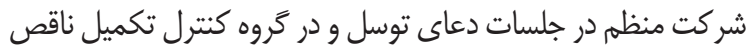

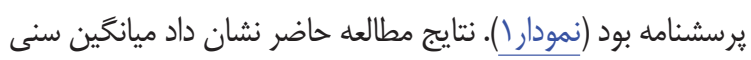

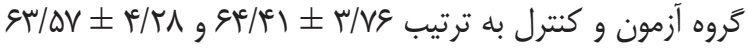

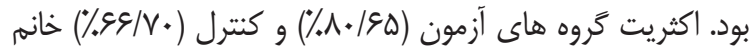

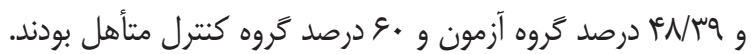

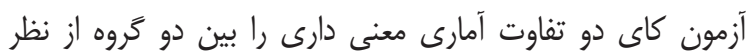

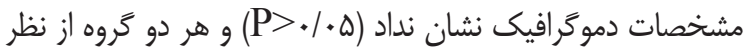
اين متغيرها همًَن بودند (جدول هاى ( و r). 


\begin{tabular}{|c|c|c|c|}
\hline \multirow[t]{2}{*}{ P-value } & 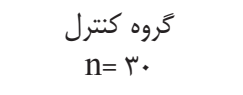 & 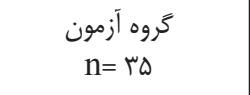 & \multirow{2}{*}{ متغير } \\
\hline & انحراف معيار 土 ميانخين & انحراف معيار 土 ميانگين & \\
\hline $\begin{array}{l}\mathrm{t}=1 / 8 \mid \\
\mathrm{P}=\cdot / 1 \\
\mathrm{t}=\cdot|\varnothing| \\
\mathrm{P}=\cdot / \Delta r\end{array}$ & $\begin{array}{c}g r / \Delta Y \pm F / T \Lambda \\
\Delta / r \pm 1 / q 1\end{array}$ & 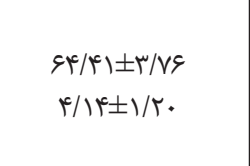 & تعداد فرزندان \\
\hline
\end{tabular}

جدول r: وضعيت مشخصات فردى (كيفى) شركت كنندًان در يثوهش در دوگروه آزمون و كنترل

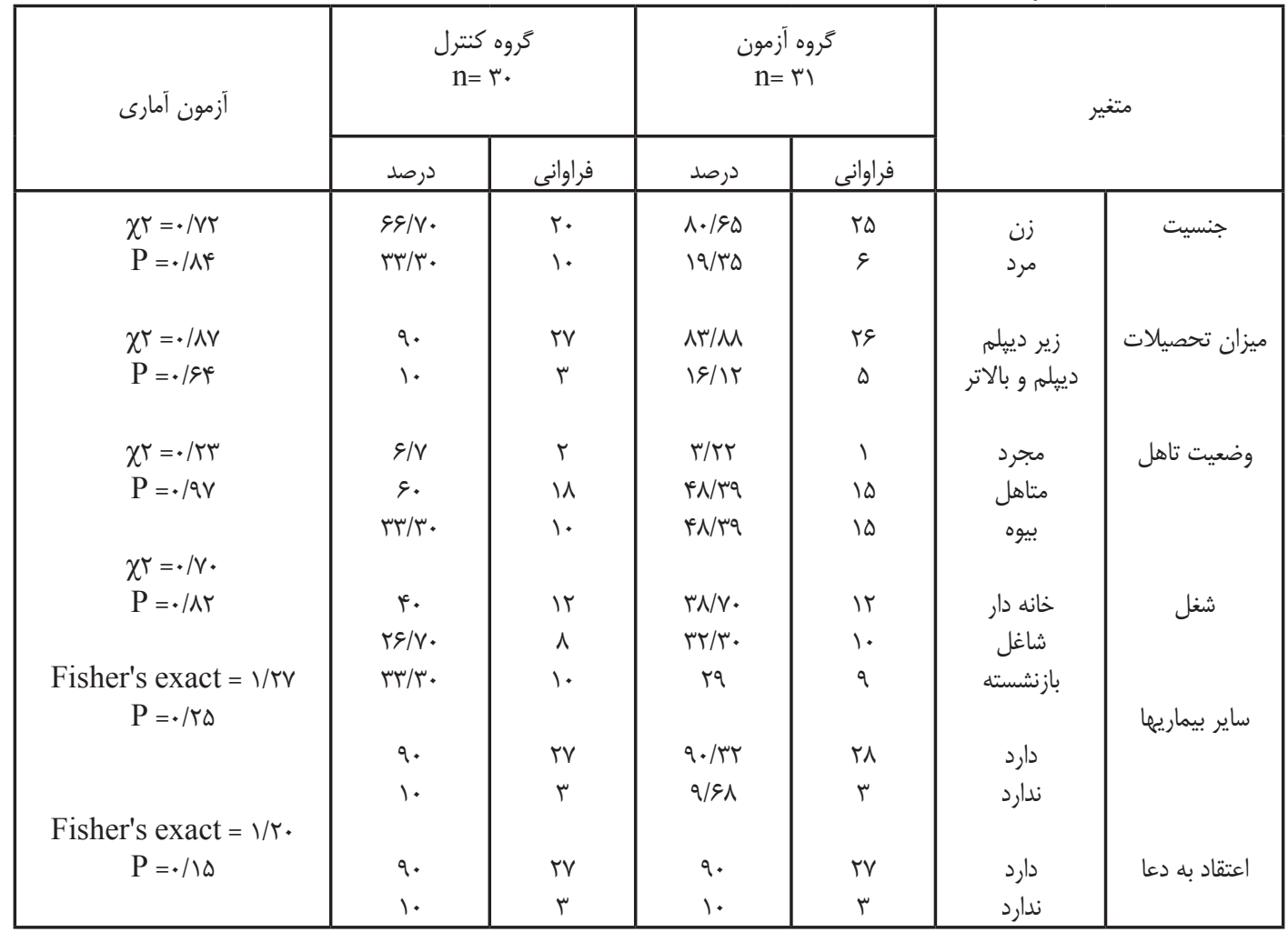

جدول سّ: مقايسه ميانكين نمره اضطراب مركَ قبل، بلافاصله بعد از آخرين جلسه و يك ماه بعد از مداخله در دو كروه آزمون و كنترل

\begin{tabular}{|c|c|c|c|c|c|c|c|}
\hline \multicolumn{3}{|c|}{$\mathrm{P}$-value } & يك ماه بعد & بلافاصله بعد & قبل ق & \multirow[t]{2}{*}{ كروه } & \multirow[t]{2}{*}{ متغير } \\
\hline عامل گروه & عامل زمان × عروه & عامل زمان & Mean \pm S.D & Mean \pm S.D & Mean \pm S.D & & \\
\hline $\mathrm{P}<\cdot / \cdot \cdot 1$ & $\mathrm{P}<\bullet / .+1$ & $\mathrm{P}<\cdot / \cdot \cdot 1$ & $\begin{array}{l}r / \varepsilon \pm 1 / \Lambda \\
\Lambda / \varepsilon \pm r / q \\
t=r / q 1 \\
P=\cdot / \cdot 1\end{array}$ & $\begin{array}{l}r / \Delta \pm 1 / \xi \\
q / r \pm 1 / \Lambda \\
t=r q / r \\
P=\cdot / \cdot \cdot 1\end{array}$ & $\begin{array}{l}N / \Delta \pm T / V \\
V / \Lambda \pm T / r \\
\mathrm{t}=\cdot / \Lambda T r \\
\left.\mathrm{P}=\cdot /{ }^{\prime}\right)\end{array}$ & كنترل & اضطراب مرى \\
\hline
\end{tabular}

به كسانى كه اعتقادات مذهبى زيادى نداشتند، تحمل كردند (19).

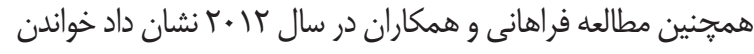
دعاى توسل باعث كاهش اضطراب مى شود (Q) (1). نعيمى و همكاران

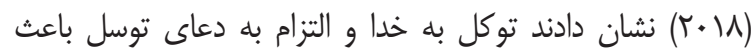
افزايش كيفيت زندگى و بهبود علائم روانشناختى در سالمندان داراى ييس ميكر مى شود (+r). مطالعه شريف نيا و همكاران نشان داد
نتايج نشان داد ميانكَين نمره اضطراب مركى در كَروه آزمون

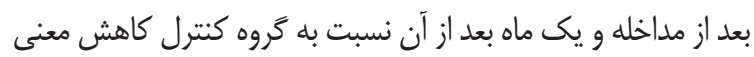

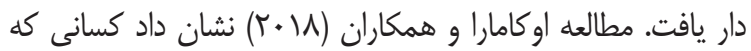

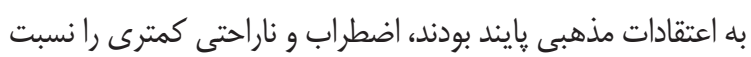


آسايش و همكارانش در سال V. •. در مطالعه خود نشان دادند كه

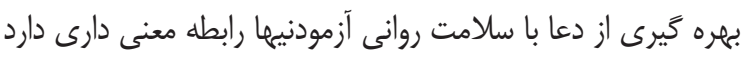

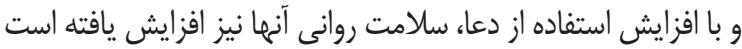

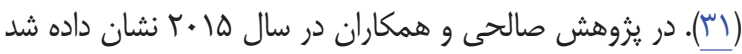

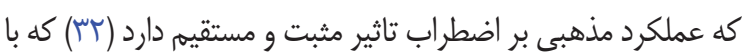
يزووهش حاضر همخوانى دارد. مطالعه خليلى و همكاران در سال • +r رابطه معنادارى را

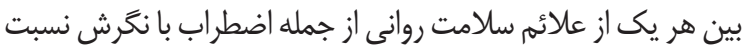
به دعاو تناوب رفتارها و فعاليت هاى مرتبط با دعا نشان داده است

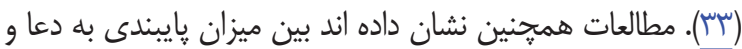

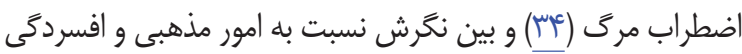
رابطه منفى وجود دارد (1)). در مطالعه نوقانى و همكاران نشان داد آموزش ارزش هاى مذهبى شامل مداخلات دعا، بخشودگى، مراقبه

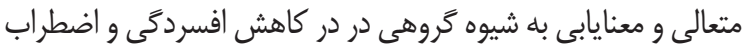

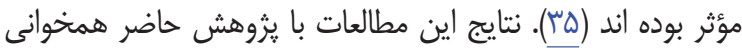

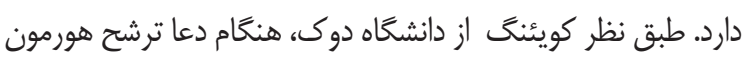
هاى كورتيزول، إيى نفرين و نورايى نفرين متوقف شده و سيستم دفاعى بدن تقويت و در نتيجه باعث آرام شدن فردو كاهش ناضن اضطراب مترفي

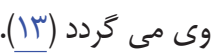

محدوديت هاى يُوهش: در طول يكماه پِ از مداخله، اتفاقات و حوادث رخ داده براى شر كت كننده ها غير قابل كنترل بود و اين وقايع در طول مطالعه ثبت مى شد.

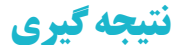

براساس يافته يزوهش حاضر مى توان جنين استنباط كرد كه كوش دادن به دعاى توسل به عنوان يك مكانيسم كنترل كننده

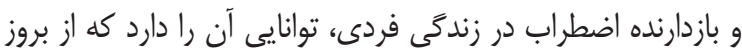

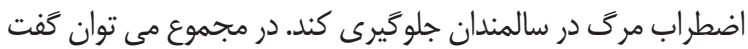
دعاو ياد خداوند به ويزه ادعيه اى كه از زبان معصومين وارد شده و وان

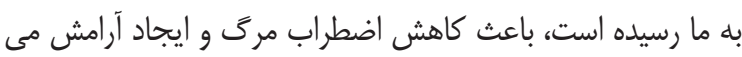
شود. ييشنهاد مى كردد در يثوهشهاى بعدى به تعيين تاثير نماز و ديخر ادعيه هاى الهى بر اضطراب مرى يرداخته شود.

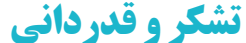

اين يزوهش حاصل پايان نامه كارشناسى ارشد سالمندى

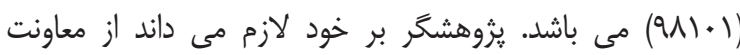
يزوهشى دانشكاه علوم يزشكى كاشان و همه سالمندان شركت كننده در يزوهش كمال قدردانى و سياس را بعمل آورد.
خواندن دعاى توسل باعث بهبود سلامت معنوى و كاهش اضطراب بيماران دياليزى مى شود (آ). نتايج اين يزوهشها با نتايج مطالعه حاضر همخوانى دارد. مطالعات نشان مى دهد توكل به خدا و توسل

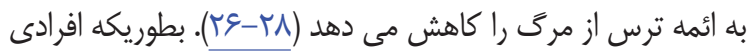

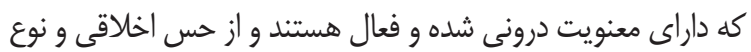
دوستى قوى برخوردارند و انكَيزه اصلى خود را در انسان بودن و حفظ كرامت او به منظور تقرب به دركاه خداوند جست وجو مى كنيند، با داردا

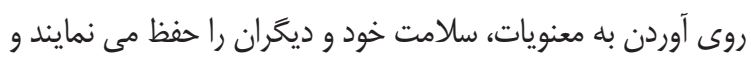
اضطراب مرك در آنها كمتر است (ع)ى). در خصوص تبيين اين نتايج، به اين نكته مى يردازيم كه سطوح مذهبى بودن و توسل به دعا در سالمندان مى تواند به كونه

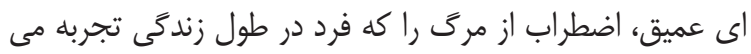
كند تحت تأثير قرار دهد. علت كاهش اضطراب مرك افرادى كه كررايش مذهبى در آنان قوى است، آن است كه آنها اعتقاد دارند

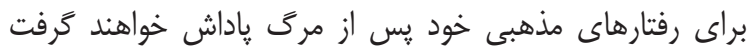

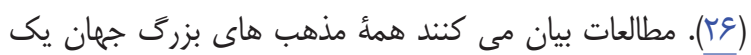

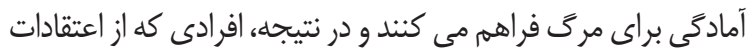
قويترى به خدا و دعا دارند، مركى را به عنوان يكى فرايند طبيعى از

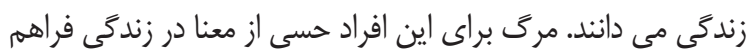
مى سازد. با رسيدن فرد به مرحلة سالمندى، علاقه به معنويات، خدا، نماز و دعا در او تقويت مى شود و معنويت به عنوان يكى از نيازهاى

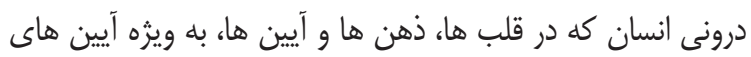

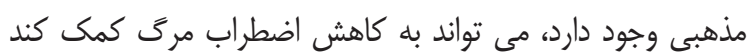

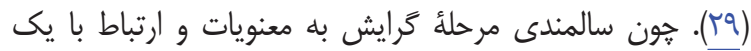
نيروى متعالى و گَست ارتباط با دنياست، ازاين رو، دعا درمانى

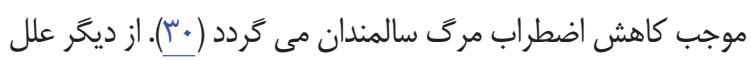
اثربخشى دعا درمانى، كمك به مراجعان در رويارويى با واقعيت مركى كرى است. آكاهى از مركَ، حس مسئوليت يذيرى افر اد را نسبت به زندَّى

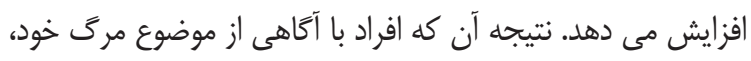

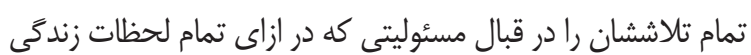

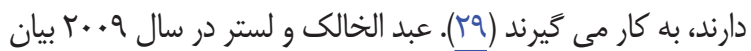
كردند كه بين اعتقادات مذهبى و توسل به خدا با اضطراب مركى

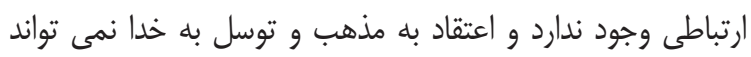

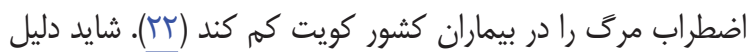
متفاوت بودن نتايج وى با يُوهش حاضر در نوع اعتقادات مذهبى بيماران و فرهنگ متفاوت آنها باشد.

در مطالعه حاضر نتايج نشان داد كَوش دادن به دعاى توسل سه بار در هفته به مدت يك ماه بر اضطر اب مرك سالمندان اثر دارد. 


\section{Refrences}

1. Mohammadpour A, Sadeghmoghadam L, Shareinia H, Jahani S, Amiri F. Investigating the role of perception of aging and associated factors in death anxiety among the elderly. Clin Interv Aging. 2018; 13: 405 - 410.

2. Krause N, Pargament KI, Ironson G. In the Shadow of Death: Religious Hope as a Moderator of the Effects of Age on Death Anxiety. J Gerontol B Psychol Sci Soc Sci. 2018; 73 (4): 696 - 703.

3. Mobasheri M, Moezi M. The prevalence of Depression among the elderly population of shaystegan and ahandidegan nursing homes in Shahrekord. Journal of Shahrekord University of Medical Sciences. 2010;12 (2):89-94.

4. Goldzweig G, Baider L, Andritsch E, Rottenberg Y. Hope and social support in elderly patients with cancer and their partners: an actor-partner interdependence model. Future Oncology. 2016; 12 (24): $2801-9$.

5. Juckel G, Mavrogiorgou P. Death anxiety and its importance for psychiatry. Fortschr Neurol Psychiatr. 2018; 86 (4): 226 - 232.

6. Zeraati M, Haghani Zemeidani M, Khodadadi Sangdeh J. The Comparison of Depression and Death Anxiety among Nursing Home Resident and Non-Resident Elderlies. IJN. 2016; 29 (102): $45-54$

7. Soleimani MA, Sharif SP, Yaghoobzadeh A, Yeoh KK, Panarello B. Exploring the Relationship Between Spiritual Well-Being and Death Anxiety in Survivors of Acute Myocardial Infarction: Moderating Role of Sex, Marital Status and Social Support. J Relig Health. 2018; 57 (2): 683 - 703

8. Nasiri M, adarvishi S, Ganjou M, Asadi M. Effect of Tavasol Prayer on Reducing Test Anxiety of New Registered Nursing Students of Ahvaz Jundishapur University of Medical Sciences. J Med Educ. 2014; 7 (15):1 - 9

9. Bassett JF, Bussard ML. Examining the Complex Relation Among Religion, Morality, and Death Anxiety: Religion Can Be a Source of Comfort and Concern Regarding Fears of Death. Omega (Westport). 2018: 30222818819343.

10. samadifard $H$, narimani $M$. Prediction of Death Anxiety of Elderly Based on Mindfulness and Irrational Beliefs. IJPN. 2017; 5 (3): 15-21.

11. Boelens PA, Reeves RR, Replogle WH, Koenig
HG. The effect of prayer on depression and anxiety: maintenance of positive influence one year after prayer intervention. Int J Psychiatry Med. 2012; 43 (1): 85-98.

12. Ekman P, Dalai L. Emotional Awareness: Overcoming the Obstacles to Psychological. 2nh ed. New York: Times Books; 2008: 78-85.

13. Koenig HG, Zaben FA, Khalifa DA. Religion, spirituality and mental health in the West and the Middle East. Asian J Psychiatr. 2012; 5 (2): 1802.

14. Rafiei R.The role of prayer on physical and mental health. Journal of Qom University of Medical Sciences.2011; 5 (3): 66-73.

15. Farmahini Farahani M, Ghamari zare $\mathrm{Z}$, Ghorbani M, purfarzad Z. Effect of Tavassol prayer on mental health of second year nursing students of School of Nursing. Complementary Medicine. 2012; 2 (2): 10-22.

16. Bahrami M, Baloochestani Asl E, Amini A, Eghbali M. The effect of two praying methods on quality of life of hospitalized cancer patients. IJNMR. 2010;15: 296 - 301

17. Dehghani Kh, Zare Rahimabadi A, Pourmovahed Z, Dehghani H, Zarezadeh A, Namjou Z. The Effect of prayer on level of anxiety in mothers of children with cancer. Iranian Journal of Pediatric Hematology Oncology. 2013;12 (2): 78 - 83.

18. Mansoori B. Prediction of death anxiety on the Basis of Quality of Relationship with God in the elderly. Culture and counseling and psychology Journal.2018: 9 (36): 145 - 162.

19. Okamura T, Shimmei M, Takase A, Toishiba S, Hayashida K, Yumiyama T, et al. A positive attitude towards provision of end-of-life care may protect against burnout: Burnout and religion in a super-aging society. PLoS One. 2018; 13 (8):e0202277.

20. Naimi E, Eilami O, Babuei A, Rezaei K, Moslemirad M. The Effect of Religious Intervention Using Prayer for Quality of Life and Psychological Status of Patients with Permanent Pacemaker. J Relig Health. 2018 Sep 14.

21. Sharifnia SH, Hojjati H, Nazari R, Qorbani M, Akhoondzade G. The effect of prayer on mental health of hemodialysis patients. Iranian Journal of Critical Care Nursing. 2012; 5 (1): 29 - 34.

22. Abdel-Khalek A, Lester D. Religiosity and death anxiety: no association in Kuwait. Psychol Rep. 
2009; 104 (3): 770 - 2.

23. Rajabi Gh, Bohrani M. Factorial analysis of death anxiety scale. Psychol J; 2001.4: 331-344.

24. Templer DI. The construction and validation of a death anxiety scale. The J Gen Psychol. 1970; $82,165-17$

25. Masoudzadeh A, Setareh J, Mohammadpour R, Modanloo kordi M. A survey of death anxiety among personnel of a hospital in Sari. J Mazandaran Univ Med Sci. 2008; 18 (67): 84 90.

26. Ghasempour A, Sooreh J, Seid tazeh kand MT. Predicting death anxiety on the basis of emotion cognitive regulation strategies. Knowl Res Appl Psychol.2012; 13 (2): 63 - 70.

27. Song Y, Cui X, Zhang Y, Gao H, Cai Q, Mu Z. Home-Based Computerized Cognitive Training for Postoperative Cognitive Dysfunction After Lung Transplantation in Elderly Population: A Randomized Controlled Trial. J Nerv Ment Dis. 2019; 207 (8): 693 - 699.

28. Asadi Shavaki M, salehi L. Knowledge, belief and practice among elderly about osteoporosis based on Health Belief Model in Karaj city in 2014. Sci J Hamadan Nurs Midwifery Fac. 2016; 24 (2): 86 - 97.

29. MacLeod R, Wilson DM, Crandall J, Austin P. Death Anxiety Among New Zealanders: The Predictive Roles of Religion, Spirituality, and Family Connection. Omega (Westport). 2017:30222817724307.

30. Krause N, Bastida E. Contact with the dead, religion, and death anxiety among older Mexican Americans. Death Stud. 2012; 36 (10): 932 - 48.

31. Asayesh H, Heidari F. the use of prayer as a spiritual approach in psychological interventions with emphasis on emam sajjad praying in sahifeieh sajjadied. Journal of Gorgan Bouyeh Faculty of nursing \& midwifery. 2007; 4 (2): 5055.

32. Salehi I, Mosalman M. Evaluation of the Relationship between Religious Attitude and Depression, Anxiety and Stress in Students of Guilan University. JRH. 2015; 3 (1):57 - 64.

33. Khalili F, Ezanlo T, Asayesh H, Abdolah tabar H. The Associalion between Praying Related Attitude and Behaviors and Students' Mental Health. JRDNM. 2010; 7 (1):55 - 62

34. Bahrami N, Moradi M, Soleimani M, Kalantari
Z, Hosseini F. Death Anxiety and its Relationship with quality of life in Women with Cancer. IJN.2013; 26 (82): 5-61.

35. Noghani F, Mohtashemi J, Vasegh Rahimparvar F, Babaei Gh. Effect of education of religious values on the rate of depression. Haiat,The Journal of Faculty of nursing \& midwifery. 2005. 23 (10): 49 - 56. 